\title{
Mucous Cyst
}

National Cancer Institute

\section{Source}

National Cancer Institute. Mucous Cyst. NCI Thesaurus. Code C83177.

A mucous containing cyst arising from the minor salivary glands in the oral cavity. 